\title{
Kinetic and stoichiometric characterization of a fixed biofilm reactor by pulse respirometry
}

\author{
Alberto Ordaz ${ }^{\mathrm{a}, \mathrm{b}}$, Catarina S. Oliveira ${ }^{\mathrm{b}}$, Guillermo Quijano ${ }^{\mathrm{a}}$, Eugenio C. Ferreira ${ }^{\mathrm{b}}$, \\ Madalena Alves $^{\mathrm{b}}$, Frédéric Thalasso ${ }^{\mathrm{a}, *}$ \\ a Centro de Investigación y de Estudios Avanzados del IPN (Cinvestav), Departamento de Biotecnología y Bioingeniería, México DF, Mexico \\ ${ }^{\mathrm{b}}$ IBB-Institute for Biotechnology and Bioengineering, Centre of Biological Engineering, University of Minho, 4710-057 Braga, Portugal
}

\section{A R T I C L E I N F O}

\section{Article history:}

Received 30 June 2011

Received in revised form

16 September 2011

Accepted 25 October 2011

Available online 9 November 2011

\section{Keywords:}

Respirometry

Fixed-bed

SBR

Biofilter

Activated sludge

Cellular growth

\begin{abstract}
A B S T R A C T
An in situ respirometric technique was applied to a sequential biofilm batch reactor treating a synthetic wastewater containing acetate. In this reactor, inoculated with mixed liquor from a wastewater plant, unglazed ceramic tiles were used as support media while maintaining complete mixing regime. A total of 8 kinetic and stoichiometric parameters were determined by in situ pulse respirometry; namely substrate oxidation yield, biomass growth yield, storage yield, storage growth yield, substrate affinity constant, storage affinity constant, storage kinetic constant and maximum oxygen uptake rate. Additionally, biofilm growth was determined from support media sampling showing that the colonization process occurred during the first 40 days, reaching an apparent steady-state afterward. Similarly, most of the stoichiometric and kinetic parameters were changing over time but reached steady values after day 40 . During the experiment, the respirometric method allowed to quantify the amount of substrate directed to storage, which was significant, especially at substrate concentration superior to $30 \mathrm{mg} \mathrm{COD} \mathrm{L}^{-1}$. The Activated Sludge Model 3 (ASM3), which is a model that takes into account substrate storage mechanisms, fitted well experimental data and allowed confirming that feast and famine cycles in SBR favor storage. These results also show that in situ pulse respirometry can be used for fixed-bed reactors characterization.
\end{abstract}

(c) 2011 Elsevier B.V. All rights reserved.

\section{Introduction}

Submerged fixed-bed reactors, also called biofilters, are of interest for bioprocesses with low microbial growth rates. The use of support media allows (i) long microbial residence time, (ii) short hydraulic residence time with low wash-out risk, and (iii) high resistance to toxic loads (Riefler et al., 1998). Compared to suspended biomass reactors, fixed-bed reactors are also significantly more complex to characterize, mainly because of the difficulty to obtain representative samples from the support media. For characterization purposes, the use of non invasive methods is preferable. The non invasive method most commonly used is based on influent and effluent mass balance, which allows the estimation of several kinetic and stoichiometric parameters, including biomass growth (Ordaz et al., 2011). However, mass balance methods require the analysis of several pseudo steady-states similarly to the classical chemostat method (Dinçer and Kargi, 2000), which is time-consuming and does not take into account potential biofilm

\footnotetext{
* Corresponding author at: Av. IPN 2508, Colonia San Pedro Zacatenco, 07360 Mexico DF, Mexico. Tel.: +52 55 57473320; fax: +52 5557473313.

E-mail address: thalasso@cinvestav.mx (F. Thalasso).
}

accumulation and therefore process modifications between two measurements. Moreover, determination of kinetic and stoichiometric parameters requires the direct measurement of the growth limiting substrate at concentrations below or close to the affinity constant $\left(K_{S}\right)$. Kovarova-Kovar and Egli (1998) as well as Koch (1997) have pointed to the precision and accuracy of substrate measurements as the main limitation of traditional kinetic and stoichiometric parameters determination.

An alternative method is pulse respirometry, which consists in measuring the dissolved oxygen $(D O)$ concentration after the injection of a defined concentration of substrate into the system. The exogenous oxygen uptake rate $\left(O U R_{e x}\right)$ curves reflect the kinetics and stoichiometry of the aerobic biodegradation process (Kong et al., 1994; Vanrolleghem et al., 1995). Such curves are also of interest to observe transient states (Jubany et al., 2005; Riefler et al., 1998; Sipkema et al., 1998). Compared to techniques based on substrate concentration measurement, respirometry allows the retrieval of numerous parameters with relatively small experimental effort, in real time, and using a low cost probe (Chandran et al., 2008; Riefler et al., 1998).

Pulse respirometry has been previously applied to fixed-bed reactors but using external respirometers that analyze samples taken from the reactor. The use of respirometers allows a better 


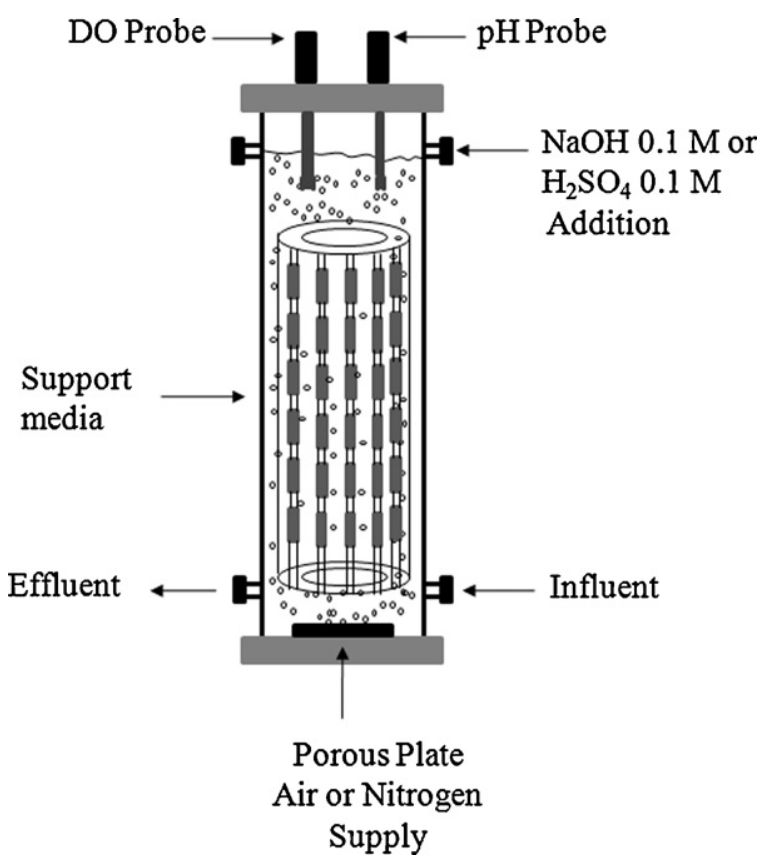

Fig. 1. Experimental set-up.

control of the test conditions and improves the results precision, but it does not discard the difficulty to obtain representative samples from the core of the reactor. To avoid sampling, Ordaz et al. (2008) applied in situ pulse respirometry, defined as pulses done directly into the reactor, for the characterization of a suspended biomass reactor. Later, Ordaz et al. (2011) applied in situ pulse respirometry in a nitrifying fixed-bed reactor and showed that in situ pulse respirometry was suitable for the direct estimation of a limited number of kinetic and stoichiometric parameters like $K_{S}$ and the maximum substrate uptake rate $\left(R_{\max }\right)$.

In the present work, in situ pulse respirometry was applied to a fixed biofilm reactor for the determination of 8 kinetic and stoichiometric parameters, during a 64 days experiment. Besides parameters determination, a special emphasis was given to support media colonization process and substrate storage mechanism. The selected process was the treatment of a synthetic wastewater containing acetate in a sequential batch reactor (SBR) and using unglazed ceramic tiles as model support media.

\section{Materials and methods}

\subsection{Experimental set-up}

A transparent acrylic reactor was used $(0.14 \mathrm{~m}$ internal diameter, $0.56 \mathrm{~m}$ height, $8.6 \mathrm{~L}$ total volume). Model support media was used to allow biofilm growth while maintaining complete mixing regime, which is an important factor for respirometric characterization. This model support media was composed of unglazed ceramic tiles $(5 \mathrm{~cm} \times 1.5 \mathrm{~cm} \times 0.7 \mathrm{~cm})$. A total of 96 tiles were suspended in 16 rows of 6 tiles each, using small fishing wires. This support media distribution allowed sampling of a row of six tiles when required for analyses (see Fig. 1). The total surface area of the support media was calculated from geometrical dimensions of each tile, excluding micropores and surface area of the wires $(0.5 \mathrm{~mm}$ diameter $)$. The surface area of the holding rod was also discarded, as no biofilm growth was observed on it. The calculated specific surface area was $460 \mathrm{~m}^{2} \mathrm{~m}^{-3}$ and the working liquid volume of the reactor with support media was $7.7 \mathrm{~L}$.

\subsection{Reactor operation}

The fixed-bed reactor was inoculated with $1 \mathrm{~L}$ of mixed liquor obtained from a municipal wastewater treatment plant in Braga, Portugal. The reactor was operated in continuous mode until a significant biomass growth was observed. After that, the reactor was operated under SBR mode with 5 cycles per day, using synthetic wastewater containing acetate as carbon source. The choice of synthetic wastewater instead of real wastewater was made to avoid composition and concentration oscillations and to allow for model development purposes. A typical SBR cycle was as follows: (i) the reactor was filled with a synthetic wastewater containing $\left(\mathrm{g} \mathrm{L}^{-1}\right)$ : $\left(\mathrm{NH}_{4}\right)_{2} \mathrm{SO}_{4}, 1.42 ; \mathrm{KH}_{2} \mathrm{PO}_{4}, 0.13 ; \mathrm{CaCl}_{2}, 0.14 ; \mathrm{MgSO}_{4}, 0.12 ; \mathrm{FeSO}_{4}$, $0.05 ; \mathrm{NaHCO}_{3}, 1.00$. This feeding period lasted for about $8 \mathrm{~min}$; (ii) a period with no feeding was maintained for $10 \mathrm{~min}$ in order to stabilize $\mathrm{pH}$ and $\mathrm{DO}$ readings; (iii) the desired volume of a concentrated acetate solution $\left(\mathrm{CH}_{3} \mathrm{COONa}, 6.31 \mathrm{~g} \mathrm{~L}^{-1}\right)$ was automatically fed to the system, which lasted from 1 to $8 \mathrm{~min}$, depending of the required substrate concentration; (iv) the degradation phase was maintained for $150-350 \mathrm{~min}$ to allow for a complete acetate degradation, depending on the substrate concentration and degradation rate; and (v) the reactor was emptied within approximately $6 \mathrm{~min}$ before another cycle was started. Reactor filling and emptying were done using peristaltic pumps (Watson Marlow, $405 \mathrm{U} / \mathrm{R} 1$, USA). At each feeding cycle, the amount of concentrated substrate added was varied in order to reach different substrate concentrations in the reactor. For respirometric reasons (see section on respirometric method and parameters estimation), five cycles of different $\operatorname{COD}\left(\mathrm{mg} \mathrm{L}^{-1}\right)$ concentrations were done every day in the following sequence: $55.0 \pm 1.4 ; 6.9 \pm 0.2 ; 27.7 \pm 0.7 ; 13.8 \pm 0.4 ;$ and $41.3 \pm 1.0$. According to these feeding periods, the total organic loading rate of the reactor was $145 \mathrm{mg} \mathrm{COD} \mathrm{L}^{-1} \mathrm{day}^{-1}$.

Air was continuously supplied through a porous plate $(0.09 \mathrm{~m}$ diameter) located at the bottom of the reactor with a constant flow rate of $0.6 \mathrm{~L} \mathrm{~min}^{-1}$. The air flow rate was controlled by a mass flowcontroller (Aalborg, Model GFC 17, Denmark) and confirmed with a variable area flow-meter (Cole-Parmer, USA). The $\mathrm{pH}$ was maintained at $7.5 \pm 0.02$ with $\mathrm{NaOH} 1 \mathrm{M}$ addition using a $\mathrm{pH}$ controller (WTW, Model Quadroline 296, Germany). Dissolved oxygen was measured with a polarographic probe and a dissolved oxygen bench meter (HI2400, Hanna Instruments, USA) connected to a PC for data acquisition. The probe included temperature data logger and automatic temperature compensation. The oxygen probe was placed at the top of the reactor. The oxygen probe was calibrated twice a week using nitrogen $(0 \%)$ and air $(100 \%)$ injected in a sample of sterilized mixed liquor obtained from the reactor. The reactor was maintained at ambient room temperature $\left(19-20^{\circ} \mathrm{C}\right)$. During respirometric experiments, temperature of the liquid phase was stable (within $\pm 0.2^{\circ} \mathrm{C}$ variation).

\subsection{Analytical procedures}

Influent and effluent were characterized through triplicate measurements of the total and soluble COD, determined using the closed reflux colorimetric method, using a laboratory digester and a spectrophotometer (HT200S and DR2800, respectively, Hach Lange, UK). Substrate concentration $(S)$ was considered to be the soluble COD fraction. Biomass concentration growing on the model support media was measured by dry weight according to Milferstedt et al. (2006), and by COD measurements. Before reactor start-up, each tile was: (i) dried at $100^{\circ} \mathrm{C}$ up to constant weight ( $48 \mathrm{~h}$ ); (ii) marked; (iii) weighted; and (iv) then placed into the reactor. During the experiment, from time to time, a row of six tiles was extracted from the reactor and dried during $48 \mathrm{~h}$ at $100^{\circ} \mathrm{C}$. The six dried tiles were weighted and then separately submerged in a known volume of distilled water and sonicated for $60 \mathrm{~min}$. 
Biomass concentration in the sonicated water sample was then determined by COD determination. Acetate was measured by HPLC (Jasco Plataform Pro, UK) with a Varian Metacarb 67H column, $\mathrm{H}_{2} \mathrm{SO}_{4} 5 \mathrm{mM}$ as mobile phase, flow rate of $0.7 \mathrm{~mL} \mathrm{~min}^{-1}$, pressure range from 70 to $80 \mathrm{~kg} \mathrm{~cm}^{-2}$, oven temperature of $60^{\circ} \mathrm{C}$ and UV detector at $210 \mathrm{~nm}$.

The oxygen mass transfer coefficient $\left(k_{L} a\right)$ was measured with the dynamic method as described by Badino et al. (2000). $k_{L} a$ was measured in triplicate, once per day after the reactor was filled and before acetate pulse was injected. All $D O$ measurements were done taking into account the response time of the $D O$ electrode $(\tau)$, characterized as the time necessary to reach $63 \%$ of the actual DO concentration when exposed to a step change (Eq. (1)). In Eq. (1), $C$ is the measured $D O$ concentration while $C^{\prime}$ is the actual $D O$ concentration. $\tau$ was estimated by passing the $D O$ electrode from water previously flushed with nitrogen to saturated water.

$\frac{d C}{d t}=\frac{1}{\tau}\left(C^{\prime}-C\right)$

\subsection{Mixing time characterization}

The hydrodynamic behavior of the reactor during pulse injection was characterized by the mixing time $\left(t_{\text {mix }}\right)$, determined by a lithium tracer technique (Séguret et al., 2000). The following procedure was used: (i) a known concentration of lithium chloride (Analytical grade, Sigma-Aldrich, USA) was injected at the bottom of the reactor; (ii) samples were taken from the top of the reactor; and (iii) after stable lithium concentration was observed, the reactor was emptied and the normal SBR operation was resumed. The samples taken from the reactor were filtered $(0.45 \mu \mathrm{m})$ and analyzed immediately by atomic absorption (Varian SPECTRAA 250 Plus, USA), after proper calibration. In order to make it comparable to $\tau$ (Eq. (1)), $t_{\text {mix }}$ was defined as the time required to reach a lithium concentration of $63 \%$ of the final lithium concentration.

\subsection{Respirometric method and parameters estimation}

In terms of oxygen balance, each SBR cycle was similar to a respirometric pulse. This method was previously used by Karahan et al. (2006). For each cycle, after the injection of a known substrate concentration $\left(S_{C}\right)$, the $D O$ concentration in the reactor was described by a balance between the exogenous respiration rate of the microorganisms $\left(O U R_{e x}\right)$ and the oxygen provided by continuous aeration (Eq. (2)). Eq. (2) takes into account the response time of the process $\left(t_{r}\right)$ as suggested by Vanrolleghem et al. (2004). More specifically, $t_{r}$ is the time constant of transient phenomenon observed following the substrate addition, including substrate and oxygen diffusion through biofilm as well as the sequence of intracellular reactions involved in substrate degradation. Eq. (2) assumes a complete mixing regime, as it will be discussed in Section 3.

$\frac{d C}{d t}=\left(k_{L} a \cdot\left(C_{b}-C\right)-O U R_{e x} \cdot\left(1-e^{t / t r}\right)\right) \cdot\left(1-e^{-t / \tau}\right)$

OUR $R_{e x}$ was described by a simple Monod kinetic (ASM1) and a more complex model (ASM3). ASM1 is an unstructured model for the simulation of oxygen and substrate consumption associated with biomass growth and ASM3 is a partially structured model that takes into account substrate storage mechanisms. The choice of these two models was based on their simplicity and their wide application in the field of respirometry. A proper description of these models can be found elsewhere (Gujer et al., 1999; Henze et al., 1987).

Three different methods were used to estimate the kinetic and stoichiometric parameters, namely direct interpretation of respirograms, pulses of increasing concentration or model fitting (Table 1). $Y_{X / S}$ and $Y_{\mathrm{O}_{2} / S}$, which are parameters of both ASM1 and
Table 1

Methods used for parameters determination.

\begin{tabular}{lll}
\hline Parameter & Model used & Method \\
\hline$Y_{\mathrm{O}_{2} / S}$ & ASM1/ASM3 & Direct interpretation of respirograms \\
$Y_{X / S}$ & ASM1/ASM3 & Direct interpretation of respirograms \\
$Y_{X S t o / S}$ & ASM3 & Direct interpretation of respirograms \\
$Y_{X / X S t o}$ & ASM3 & Direct interpretation of respirograms \\
$K_{S}$ & ASM1/ASM3 & Pulses of increasing concentration \\
OUR $R_{\text {exmax }}$ & ASM1/ASM3 & Pulses of increasing concentration \\
$K_{S t o}$ & ASM3 & Model fitting \\
$k_{S t o}$ & ASM3 & Model fitting \\
$t_{r}$ & ASM1/ASM3 & Model fitting \\
$X$ & ASM3 & Model fitting \\
\hline
\end{tabular}

ASM3 models, were estimated from a direct interpretation of the respirograms area according to Eq. (3), as previously described (Ordaz et al., 2008).

$Y_{X / S}=1-Y_{\mathrm{O}_{2} / S}=1-\frac{k_{L} a \cdot \int_{0}^{t}\left(C_{b}-C\right) d t+\left(C_{0}-C_{f}\right)}{S_{C}}$

In ASM3, the overall $Y_{X / S}$ can be divided in two partial yields. Indeed, ASM3 considers that the substrate is first consumed for storage and then bacteria consume storage material for growth (Goel et al., 1999; Guisassola et al., 2005; Karahan et al., 2002; Van Loosdrecht et al., 1997). Two growth yields are therefore defined; storage yield $\left(Y_{X S t o / S}\right)$, and storage growth yield $\left(Y_{X / X S t o}\right)$. Both parameters were estimated from direct interpretation of the respirograms, according to Eqs. (4) and (5) (Goel et al., 1999; Karahan et al., 2002). Fig. 2 shows an example of a typical respirogram observed after the injection of a substrate pulse of $41.3 \pm 1.0 \mathrm{mg} \mathrm{COD} \mathrm{L}^{-1}$. In Eqs. (4) and (5) as well as in Fig. 2, $C_{L S t o}$ is the baseline of oxygen consumption for storage and represents the limit between oxygen consumption for storage (Area I, Fig. 2) and oxygen consumption for growth (Area II, Fig. 2) as suggested earlier by Karahan et al. (2002, 2006). In the present work, $C_{L S t o}$ was estimated after drawing a line A-B between the origins of the $D O$ curve to the inflection point observed during the $D O$ ascending part (line A-B, Fig. 2).

$Y_{X S t o / S}=1-\frac{k_{L} a \cdot \int_{0}^{t}\left(C_{L S t o}-C\right) d t}{S_{C}}$

$Y_{X / X S t o}=\frac{Y_{X / S}}{Y_{X S t o / S}}$

$K_{S}$ and OUR $R_{\text {exmax }}$, which are parameters of both ASM1 and ASM3 models, were determined after the injection of pulses of increasing concentration, similarly to the method previously reported by Orupold et al. (2001). In the present work, the feeding strategy allowed to obtain respirograms at several substrate

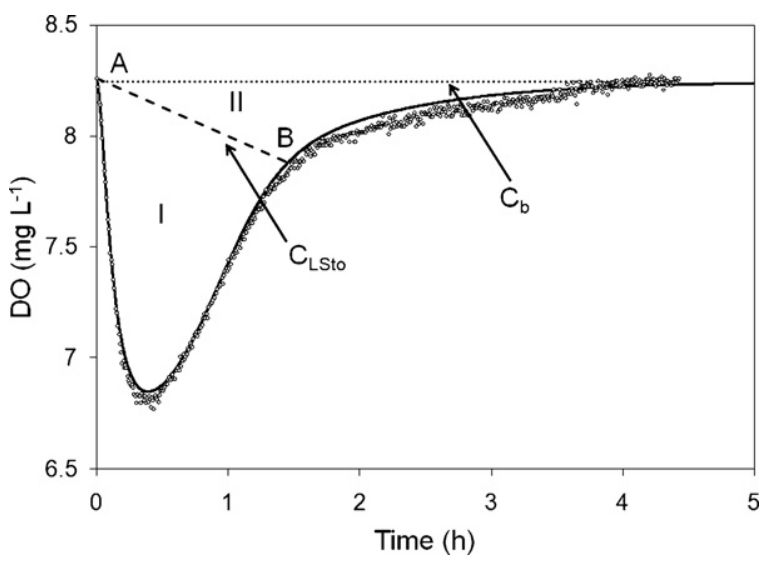

Fig. 2. Typical respirogram observed after pulse injection (see text). 


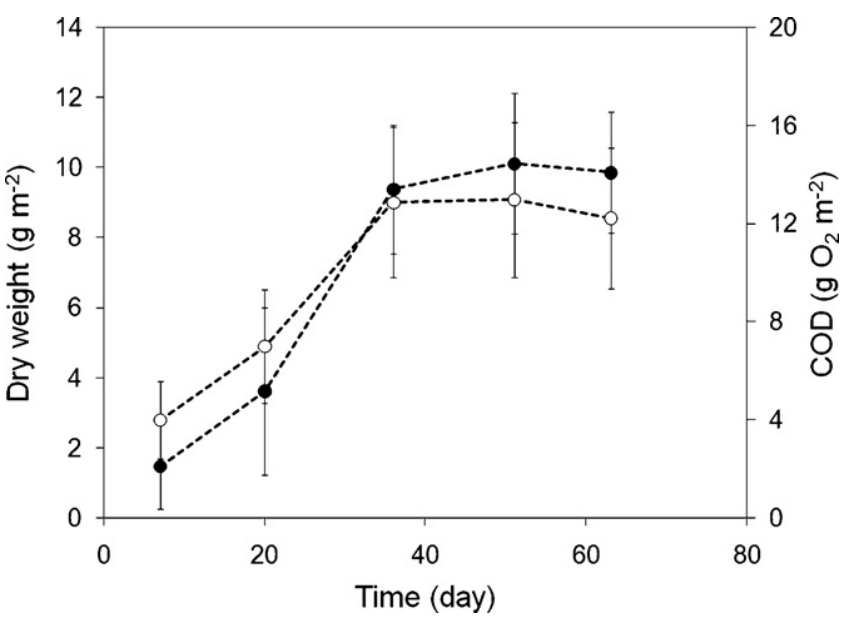

Fig. 3. Biomass concentration in the biofilm reactor: $\operatorname{COD}(\bigcirc)$, and dry weight (

concentrations. For each set of respirograms (5 respirograms obtained per day), the observed maximum oxygen uptake rate $\left(O U R_{\text {exmax }}^{\prime}\right)$ was plotted against the actual substrate concentration $\left(S_{t}\right)$ by the time $O U R_{\text {exmax }}^{\prime}$ was observed (Eq. (6)). As it will be discussed in Section 3, the resulting graphs showed a clear Monodtype shape that was used to estimate $O U R_{\text {exmax }}$ and $K_{S}$, after Hannes Woolf linearization (Duarte et al., 1994). In order to compensate for the reduction of support media due to sampling, OUR exmax were expressed per unit of support area in the reactor.

$S_{t}=S_{C} \cdot \frac{\int_{0}^{t} O U R_{e x} d t}{Y_{\mathrm{O}_{2} / S}}$

$K_{\text {Sto }}, k_{\text {Sto }}, X$ and $t r$, were obtained by adjustment of ASM1 (Monod kinetic) or ASM3 (Table 2) to the experimental data with a fitting procedure based on Runge-Kutta method and the parameters were optimized with a Marquardt optimization method (Model Maker, Cherwell Scientific Publishing, UK). The goodness of fit was determined by the correlation factors $\left(r^{2}\right)$ and the $P$-values. When ASM3 was used, the endogenous respiration rate of biomass $\left(b_{h}\right)$ and the endogenous respiration rate of storage material $\left(b_{\text {Sto }}\right)$ were set to default values; $8.3 \times 10^{-3} \mathrm{~g} \mathrm{O}_{2} \mathrm{~g}^{-1} \mathrm{Xh}^{-1}$ and $8.3 \times 10^{-3} \mathrm{~g} \mathrm{O}_{2}{ }^{-1}$ $X_{S t o} \mathrm{~h}^{-1}$, respectively (Karahan et al., 2002). In the matrix representation of ASM3, $\mu_{\max }$ was substituted by Eq. (7).

$\mu_{\max }=\frac{\text { OUR }_{\text {ex max }} \cdot Y_{X / S}}{Y_{\mathrm{O}_{2} / S} \cdot X}$

In order to account for suspended biomass activity during respirometric tests, samples of the effluent mixed liquor were taken and tested in a commercial respirometer (YSI 5300A, YSI, USA). In that respirometer, pulse experiments were done by injecting a known amount of synthetic wastewater and suspended biomass concentration was estimated from the difference between total and soluble COD.

\section{Results and discussion}

\subsection{Support media colonization}

After inoculation, the reactor was operated continuously for 3 days, at a dilution rate of $0.02 \mathrm{~h}^{-1}$ with an acetate concentration of $30 \mathrm{mg} \mathrm{COD} \mathrm{L}^{-1}$. At day 4 , the suspended biomass was removed from the reactor and the $S B R$ operational mode was started with 5 cycles per day, corresponding to a total organic loading rate of $0.145 \mathrm{~g}$ $\mathrm{COD} \mathrm{L}^{-1} \mathrm{day}^{-1}$. Fig. 3 shows the biomass concentration observed on the support media. From the onset of the reactor operation and until day 40 , the support media was progressively colonized reaching a final concentration of $9.8 \pm 1.8 \mathrm{~g}$ dry-biomass $\mathrm{m}^{-2}$ and $12.7 \pm 3.1 \mathrm{~g}$ COD-biomass $\mathrm{m}^{-2}$. After day 40 , the carrier was not further colonized and the substrate degradation rate as well as the biomass concentration in the effluent remained constant (data not shown). This suggests that the reactor reached a pseudo steady-state by day 40. Afterwards, the COD/weight ratio of the fixed biomass was $1.29 \pm 0.07$ which is close to the COD/weight ratio of the microbial biomass composition usually accepted $\left(\mathrm{C}_{5} \mathrm{H}_{7} \mathrm{NO}_{2}\right.$, ratio of 1.41) and within the range of 1.2-1.6 reported by Contreras et al. (2002) for pure cultures and activated sludge systems.

\subsection{Mixing characterization}

Before starting the respirometric experiments, $\tau$ was estimated to $19 \pm 2 \mathrm{~s}$ and the mixing regime of the reactor was evaluated. In the absence and the presence of support media, $t_{m i x}$ was $16 \pm 2$ and $18 \pm 4 \mathrm{~s}$, respectively. Compared to the duration of the pulses; i.e. typically from 1 to $5 \mathrm{~h}$, these observed mixing times were negligible and the reactor was therefore considered as completely mixed. Similarly, as the mixing times with and without support media were not significantly different $(P<0.05)$, the support media was considered as without effect on the reactor mixing regime. Vanrolleghem et al. (2004) and Einsele et al. (1978) suggested that when $t_{m i x}$ is significantly higher than $t_{r}$, the DO response observed immediately after substrate pulses injection, is affected by mixing regime. Mixing may therefore affect kinetic characterization, if not considered by the respirometric model. As it will be shown hereafter, in this work, the response time of the process was estimated to $40 \mathrm{~s}$, which is significantly higher than $t_{m i x}$. It was therefore considered that mixing occurred significantly faster than the transient phenomenon and did not contribute significantly to the observed DO response.

\subsection{OUR $R_{\text {exmax }}$ and $K_{S}$ determination}

Fig. 4A shows an example of respirograms obtained at day 17 , after the injection of five different substrate amounts $\left(S_{C}\right.$ of 6.9 , 13.8, 27.7, 41.3, and 55.0 $\mathrm{mg} \mathrm{COD} \mathrm{L}^{-1}$ ). Fig. 4B shows the OUR ${ }_{\text {exmax }}^{\prime}$ against $S_{t}$ plot, where a typical Monod curve can be seen. The Hannes Woolf linearization fitted well the results obtained in Fig. 4B $\left(r^{2}: 0.987 \pm 0.019\right)$ and allowed the determination of $O U R_{\text {exmax }}$ and $K_{S}$. The same strategy was used along the entire reactor operation and similar model fitting were obtained (average $r^{2}: 0.981 \pm 0.023$ ). In order to account for potential suspended biomass activity, respirometric pulses experiments were done, every 5 days, with samples of the effluent suspended biomass. No response to substrate pulses was observed (data not shown). This low activity was explained by low suspended biomass concentration, namely below COD detection limit $\left(2 \mathrm{mg} \mathrm{COD} \mathrm{L}^{-1}\right)$, all along the experiment. For comparison, as it will be shown hereafter, the corresponding fixed biomass concentration was between 1.8 and $6.0 \mathrm{~g} \mathrm{COD} \mathrm{L}^{-1}$. Suspended biomass activity was therefore considered insignificant.

Fig. 5A shows that $O U R_{\text {exmax }}$, expressed per unit of support area, increased and reached a maximum value of $1300 \mathrm{mg} \mathrm{O}_{2} \mathrm{~h}^{-1} \mathrm{~m}^{-2}$ at day 22. After day 22, OUR exmax $_{\text {decreased and stabilized, after }}$ day 40 , to approximately $766 \pm 53 \mathrm{mg} \mathrm{O}_{2} \mathrm{~h}^{-1} \mathrm{~m}^{-2}$. According to the observed $Y_{\mathrm{O}_{2} / \mathrm{S}}$, this OUR exmax $_{\text {corresponded to a maximum }}$ acetate degradation rate of $2051 \pm 185 \mathrm{mg} \mathrm{h}^{-1} \mathrm{~m}^{-2}$. The decrease observed between days 22 and 40, might be related to modifications in biofilm structure or diffusion limitation. A similar behavior was observed with $K_{S}$. The apparent $K_{S}$ started at values of $10 \mathrm{mg} \mathrm{L}^{-1}$, increased during the first 22 days up to $30 \mathrm{mg} \mathrm{L}^{-1}$ and then, decreased before stabilizing at $20 \pm 2 \mathrm{mg} \mathrm{L}^{-1}$, after day 40 . These results may also be related to modification of biofilm structure or to a shift in microbial population. The $K_{S}$ values obtained 
Table 2

Simplified matrix of ASM3 for organic carbon removal, considering soluble biodegradable COD.

\begin{tabular}{|c|c|c|c|c|c|}
\hline Component process & $S$ & $X_{\text {Sto }}$ & $X$ & C & Rate \\
\hline Storage of $S$ & -1 & $Y_{X s t o / S}$ & & $-\left(1-Y_{X s t o / S}\right) / Y_{X s t o / S}$ & $k_{S t o} \cdot X \cdot \frac{S}{S+K_{S}}$ \\
\hline Growth on $X_{\text {Sto }}$ & & $-1 / Y_{X / X s t o}$ & 1 & $-\left(1-Y_{X / X s t o}\right) / Y Y_{X / X s t o}$ & $\mu_{\max } \cdot X \cdot \frac{X_{S t o} / X}{\left(X_{S t o} / X\right)+K_{S t o}}$ \\
\hline Endogenous respiration & & & -1 & & $b_{h} \cdot X$ \\
\hline Respiration of $X_{S t o}$ & & -1 & & & $b_{\text {Sto }} \cdot X_{\text {Sto }}$ \\
\hline
\end{tabular}

were clearly superior to the range reported in the literature for suspended cultures (i.e. $0.5-3 \mathrm{mg} \mathrm{L}^{-1}$; Guisassola et al., 2005; Hoque et al., 2009). This could be due to the presence of the biofilm, as Gonzalez-Gil et al. (2001) reported that $K_{S}$ for acetate increased almost 10 times when an anaerobic culture was growing in granular form, compared to suspended biomass.

\section{4. $Y_{X S t o / S}, Y_{X / X S t o}, Y_{O_{2} / S}$ and $Y_{X / S}$ determination}

Fig. 5B shows the $Y_{X / S}$ profile observed during the experiment. It was observed that during the first 12 days, $Y_{X / S}$ was $0.53 \pm 0.04$. After day $13, Y_{X / S}$ decreased to $0.37 \pm 0.03$, while after day 37 the value increased again to $0.51 \pm 0.05$.

$Y_{X / S}$ is the overall yield of the system and involves the substrate utilization and growth either on soluble or stored substrate. However, SBR operation induces a succession of feast and famine cycles, which is known to promote storage mechanisms (Guisassola et al., 2005; Karahan et al., 2006; Van Loosdrecht et al., 1997). Additionally, Karahan et al. (2002), showed that when there is a change from a famine to a feast period, the microorganism may respond differently, depending on the $S / X$ ratio. At high $S / X$
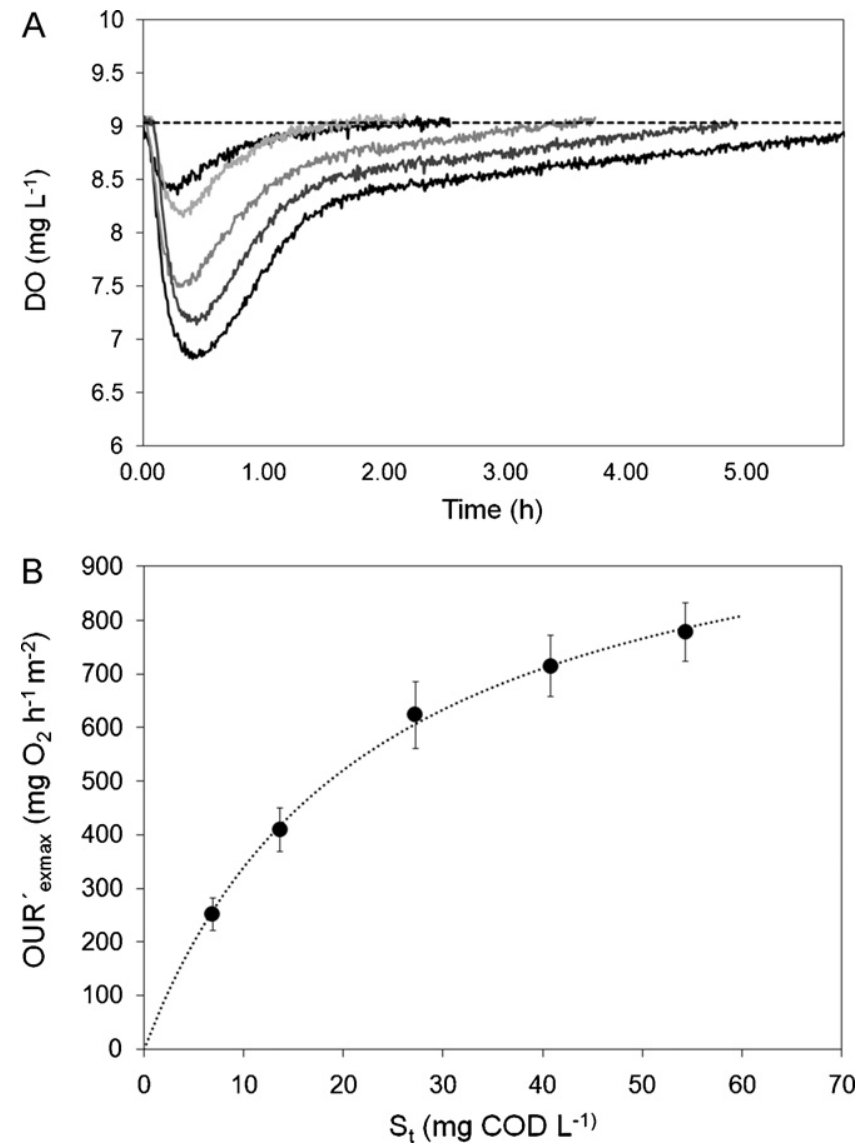

Fig. 4. (A) $D O$ concentration observed at different $S_{C}$. (B) Monod curve of $O U R^{\prime}{ }_{\text {exmax }}$ at different $S_{t}$. ratio, the storage process is preferential over the growth process, whereas the contrary is observed at low $S / X$ ratio. Taking that into account, Fig. 5B shows $Y_{X S t o / S}$ observed along the experiment, for the minimum and maximum pulse concentrations tested during the experiment, i.e. $6.92 \pm 0.18$ and $55.04 \pm 1.42 \mathrm{mg} \mathrm{L}^{-1}$, respectively. For the higher pulse concentration, $Y_{X S t o / S}$ was roughly constant along the reactor operation. On the contrary, with the lowest pulse concentration a clear decrease of $Y_{X S t o / S}$ was observed. This decrease can be explained by the increase of the biomass concentration in the reactor, decreasing further the $S / X$ ratio and promoting growth over storage. The $Y_{X S t o / S}$ values observed in Fig. $5 \mathrm{~B}$ at the higher pulse concentration, i.e. from 0.7 to 0.75 , are within the range reported in the literature (0.66-0.97; Carucci et al., 2001; Gujer et al., 1999; Hoque et al., 2009; Karahan et al., 2002).

To further analyze the impact of substrate concentration, Fig. 6A shows the average $Y_{X S t o / S}$ and $Y_{X / X S t o}$ observed at each one of the five pulses concentrations $\left(S_{C}\right.$ of $6.9,13.8,27.7,41.3$, and $55.0 \mathrm{mg}$ $\mathrm{COD} \mathrm{L}^{-1}$ ) during the 64 days of the experiment. No significant difference of $Y_{X / S}$ was observed but storage $\left(Y_{X S t o / S}\right)$ was significantly more important at higher $S_{C}$, and growth $\left(Y_{X / X S t o}\right)$ was promoted by low $S_{C}$. An 8 -fold increase of $S_{p}$ caused a $32 \%$ increase of $Y_{X S t o / S}$ and a 34\% decrease of $Y_{X / X S t o}$. These results therefore confirm what earlier suggested by Karahan et al. (2002) about the effect of the $S / X$ ratio on storage.

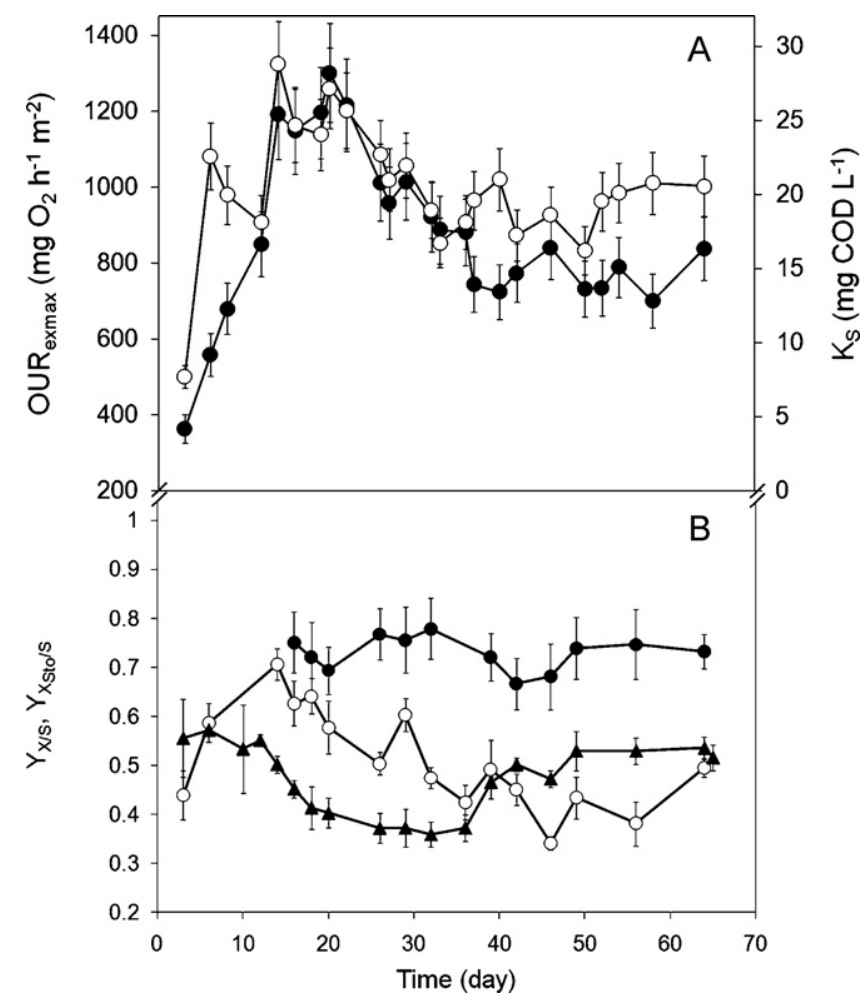

Fig. 5. (A) $O U R_{\text {exmax }}(\bullet)$, and $K_{S}(\bigcirc)$. (B) $Y_{X / S}(\boldsymbol{\Delta}), Y_{X S t o / S}$ at $S_{C}$ of $6.92 \mathrm{mg} \mathrm{COD} \mathrm{L}^{-1}(\bigcirc)$, and $55.04 \mathrm{mg} \mathrm{COD} \mathrm{L}^{-1}(\bullet)$ 
Table 3

Average kinetic parameters retrieved from the adjustment of ASM3 to the experimental data.

\begin{tabular}{|c|c|c|c|c|}
\hline Parameter & Value & $\sigma$ & $r^{2}$ & $P$-value \\
\hline$K_{\text {Sto }}\left(\mathrm{mg} \mathrm{COD} \mathrm{mg}{ }^{-1} \mathrm{COD}\right)$ & 0.31 & 0.52 & & \\
\hline$k_{\text {Sto }}\left(\mathrm{h}^{-1}\right)$ & 0.16 & 0.09 & $0.960 \pm 0.023$ & $<0.0105$ \\
\hline$t_{r}(\mathrm{~s})$ & 40.3 & 50.4 & & \\
\hline
\end{tabular}

\section{5. $K_{\text {Sto }}$, and $k_{\text {Sto }}$ determination}

Fig. 6B shows the correlation factor $\left(r^{2}\right)$ of ASM1 and ASM3 models to the experimental data. ASM1 described adequately the experimental data for $S_{C}$ of $6.92,13.85$ and $27.69 \mathrm{mg} \mathrm{COD} \mathrm{L}^{-1}$ with an average $r^{2}$ of 0.951 , when lower storage $\left(Y_{X S t o / S}\right)$ was observed. With $S_{C}$ of 41.32 and $55.04 \mathrm{mg} \mathrm{COD} \mathrm{L}^{-1}$, ASM1 model showed poor fitting to the experimental data, with an average $r^{2}$ of 0.787 . ASM3 had a better adjustment to the experimental data in all the range of $S_{C}$ tested. The same conclusion was reached from $P$-value estimation, with ASM3 model being more significant at higher substrate concentrations than ASM1. Consequently, ASM3 model was chosen to further characterize the fixed-bed process, namely, the storage affinity constant $\left(K_{S t o}\right)$, the storage kinetic constant $\left(k_{S t o}\right)$ and the response time of the process $\left(t_{r}\right)$.

$K_{S t o}, k_{S t o}$ and $t_{r}$ as well as the standard deviation $(\sigma)$ for each parameter are shown in Table 3. Table 3 also shows the average correlation factor $\left(r^{2}\right)$ and $P$-value of ASM3 fitting to experimental data. $K_{S t o}$, was slightly below the range reported in the literature for suspended cultures; $0.6-1 \mathrm{mg}$ COD mg ${ }^{-1}$ COD (Guisassola et al., 2005; Gujer et al., 1999; Hoque et al., 2009). $k_{S t o}$, the kinetic constant of the storage material degradation was within previously reported values for suspended biomass; $0.05-0.2 \mathrm{~h}^{-1}$ (Guisassola

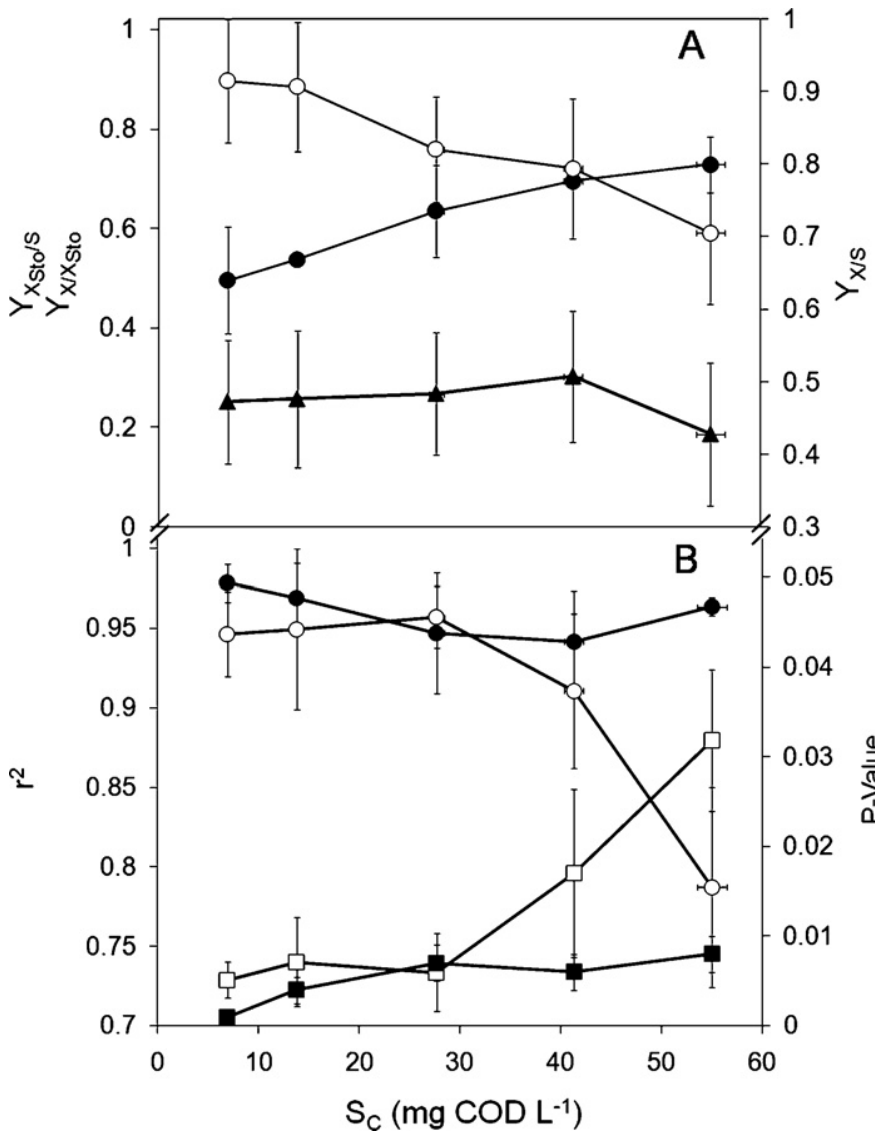

Fig. 6. (A) Profile of $Y_{X / X S t o}(\bigcirc), Y_{X S t o / S}(\bullet)$ and $Y_{X / S}(\boldsymbol{\Delta})$ ). (B) Correlation factor for ASM1 $(\bigcirc)$ and ASM3 $(\bullet)$ and $P$-value for ASM1 $(\square)$ and ASM3 $(\square)$ to $S_{C}$ of 6.92, 13.85, 27.69, 41.32 and $55.04 \mathrm{mg} \mathrm{DQO} \mathrm{L}^{-1}$. et al., 2005; Karahan et al., 2002). The response time of the process $\left(t_{r}\right)$ was approximately $40 \mathrm{~s}$, which is lower than the response time observed with acetate as substrate in a aerobic heterotrophic biomass suspended culture (95 s, Vanrolleghem et al., 2004).

\section{Conclusions}

In situ pulse respirometry was successfully applied for the characterization of a fixed-bed reactor. Combined with ASM3 model, in situ pulse respirometry allowed the estimation of 8 stoichiometric and kinetic parameters, namely $Y_{X S t o / S}, Y_{X / X S t o}, Y_{\mathrm{O}_{2} / S}, Y_{X / S}$, $K_{S}, K_{S t o}, k_{S t o}$, and OUR $R_{\text {exmax }}$. Most of these parameters are usually determined from mass balance experiments or from samples taken from the core of the reactor. Given the time required to perform mass balance experiments and the difficulty to obtain representative samples from the core of the support media, pulse respirometry is a useful tool that allows the determination of a larger number of parameters in a shorter experimental time.

However, the respirometric method used in this work is based on the assumption that the respirograms observed from the dissolved oxygen electrode location are representative of the all reactor. Mixing and hydrodynamics play therefore a decisive role on respirometry in fixed-bed. In the model reactor used, no such limitation was observed, allowing basic fixed biofilm characterization. This same strategy can be applied in a variety of bioprocesses to improve basic understanding of fixed-film growths and kinetics. The application of pulse respirometry in larger scales or with other support media might be considered, but making sure a correct interpretation of respirograms is done in light of hydrodynamic characterization.

\section{Acknowledgements}

This work has been supported by "Consejo Nacional de Ciencia y Tecnología”, Mexico (proyect 59872). We gratefully acknowledge the financial support to Alberto Ordaz and Guillermo Quijano through Grants \#208321 and \#164283, respectively, from “Consejo Nacional de Ciencia y Tecnología”, Mexico. We also acknowledge "Fundação para a Ciência e a Tecnologia", Portugal, for the financial support to Catarina S. Oliveira (Grant SFRH/BD/32289/2006).

\section{References}

Badino, A.C., Facciotti, M.C.R., Schmidell, W., 2000. Improving $k_{L} a$ determination in fungal fermentation, taking into account electrode response time. J. Chem. Technol. Biotechnol. 75, 469-474.

Carucci, A., Dionisi, D., Majone, M., Rolle, E., Smurra, P., 2001. Aerobic storage by activated sludge on real wastewater. Water Res. 35, 3833-3844.

Chandran, K., Hu, Z., Smets, B.F., 2008. A critical comparison of extant batch respirometric and substrate depletion assays for estimation of nitrification biokinetics. Biotechnol. Bioeng. 101, 62-72.

Contreras, M., Bertola, N., Giannuzzi, L., Zaritzky, N., 2002. A modified method to determine biomass concentration as COD in pure cultures and in activated sludge systems. Water SA. 26, 463-468.

Dinçer, A., Kargi, F., 2000. Kinetics of sequential nitrification and denitrification processes. Enzyme Microb. Technol. 27, 37-42.

Duarte, L.C., Nobre, A.P., Gírio, F.M., Amaral-Collaço, M.T., 1994. Determination of the kinetic parameters in continuous cultivation by Debaryomyces hansenii grown on D-xylose. Biotechnol. Tech. 8, 859-864.

Einsele, A., Ristroph, D.L., Humphrey, A.E., 1978. Mixing times and glucose uptake measured with a fluorometer. Biotechnol. Bioeng. 20, 1487-1492.

Goel, R., Mino, T., Satoh, H., Matsuo, T., 1999. Modeling hydrolysis processes considering intracellular storage. Water Sci. Technol. 39, 97-105. 
Gonzalez-Gil, G., Seghezzo, L., Lettinga, G., Kleerebezem, R., 2001. Kinetics and mass-transfer phenomena in anaerobic granular sludge. Biotechnol. Bioeng. 73, $125-134$.

Guisassola, A., Sin, G., Baeza, J.A., Carrera, J., Vanrolleghem, P.A., 2005. Limitations of ASM1 and ASM3: a comparison based on batch oxygen uptake rate profiles from different full-scale wastewater treatment plants. Water Sci. Technol. 52, 69-77.

Gujer, W., Henze, M., Mino, T., van Loosdrecht, M., 1999. Activated Sludge Model No. 3. Water Sci. Technol. 39, 183-193.

Henze, M., Grady Jr., C.P.L., Gujer, W., Marais, G.V.R., Matsuo, T., 1987. Activated Sludge Model No. 1. IAWPRC Scientific and Technical Report No. 1, London.

Hoque, M.A., Aravinthan, V., Pradhan, N.M., 2009. Assessment on activated sludge models for acetate biodegradation under aerobic conditions. Water Sci. Technol. 60, 983-994.

Jubany, I., Baeza, J.A., Carrera, J., Lafuente, J., 2005. Respirometric calibration and validation of a biological nitrite oxidation model including biomass growth and substrate inhibition. Water Res. 39, 4574-4584.

Karahan, O., Artan, N., Orhon, D., Henze, M., van Loosdrecht, M.C.M., 2002. Respirometric assessment of storage yield for different substrates. Water Sci. Technol. $46,345-352$

Karahan, O., van Loosdrecht, M.C.M., Orhon, D., 2006. Modelling the utilization of starch by activated sludge for simultaneous substrate storage and microbial growth. Biotechnol. Bioeng. 94, 43-53.

Koch, A., 1997. Microbial physiology and ecology of slow growth. Microbiol. Mol. Biol. Rev. 61, 305-318.

Kong, Z., Vanrolleghem, P., Verstraete, W., 1994. Automated respiration inhibitionkinetics analysis (ARIKA) with a respirographic biosensor. Water Sci. Technol. 30, 275-284.

Kovarova-Kovar, K., Egli, T., 1998. Growth kinetics of suspended microbial cells: from single-substrate-controlled growth to mixed-substrate kinetics. Microbiol. Mol. Biol. Rev. 62, 646-666.
Milferstedt, K., Pons, M.N., Morgenroth, E., 2006. Optical method for long-term and large-scale monitoring of spatial biofilm development. Biotechnol. Bioeng. 94, $773-782$.

Ordaz, A., Oliveira, C.S., Aguilar, R., Carrión, M., Ferreira, E.C., Alves, M., Thalasso, F., 2008. Kinetic and stoichiometric parameters estimation in a nitrifying bubble column through in situ pulse respirometry. Biotechnol. Bioeng. 100, 94-102.

Ordaz, A., Oliveira, C.S., Alba, J., Thalasso, F., 2011. Determination of apparent kinetic and stoichiometric parameters in a nitrifying fixed-bed reactor by in situ pulse respirometry. Biochem. Eng. J. 55, 123-130.

Orupold, K., Masirin, A., Tenno, T., 2001. Estimation of biodegradation parameters of phenolic compounds on activated sludge by respirometry. Chemosphere 44 , 1273-1280.

Riefler, R.G., Ahlfeld, D.P., Smets, B.F., 1998. Respirometric assay for biofilm kinetics estimation: parameter identifiability and retrievability. Biotechnol. Bioeng. 57, 35-45.

Séguret, F., Racault, Y., Sardin, M., 2000. Hydrodynamic behaviour of full scale trickling filters. Water Res. 34, 1551-1558.

Sipkema, E.M., De Koning, W., Ganzeveld, K.J., Janssen, D.B., Beenackers, A.A.C.M., 1998. Experimental pulse technique for the study of microbial kinetics in continuous culture. J. Biotechnol. 64, 159-176.

Van Loosdrecht, M.C.M., Pot, M.A., Heijnen, J.J., 1997. Importance of bacterial storage polymers in bioprocesses. Water Sci. Technol. 35, 41-47.

Vanrolleghem, P.A., Sin, G., Gernaey, K.V., 2004. Transient response of aerobic and anoxic activated sludge activities to sudden substrate concentration changes. Biotechnol. Bioeng. 86, 277-290.

Vanrolleghem, P.A., Van Daele, M., Dochain, D., 1995. Practical identifiability of a biokinetic model of activated sludge respiration. Water Res. 29, 2561-2570. 